\title{
Triclosan/Copolymer/Fluoride Toothpaste
}

National Cancer Institute

\section{Source}

National Cancer Institute. Triclosan/Copolymer/Fluoride Toothpaste. NCI Thesaurus.

Code C148541.

A fluoride-based toothpaste containing the anti-inflammatory and broad-spectrum antibacterial agent triclosan and polyvinylmethyl ether maleic acid copolymer (PVM/MA), with potential antibacterial, anti-inflammatory, and protective activities. Upon application of the triclosan/copolymer/fluoride toothpaste to the teeth, the toothpaste helps remove plaque accumulation. The fluoride protects the teeth against cavities while the triclosan prevents inflammation and may protect against ging ivitis and mucositis. The copolymer in the toothpaste enhances the uptake of triclosan by enamel and buccal epithelial cells, thereby prolonging its protective effect and enhancing its activity. 